\title{
ANTS and POTS: Do They Change Lives? Students Perceptions on the Value of Positive Psychology Concepts
}

\author{
Vikki Walters \\ CQUniversity, Australia \\ Trixie James \\ CQUniversity, Australia
}

\begin{abstract}
Positive psychology provides a different perspective to that of traditional psychology. There is a growing research base of scientific study to validate the significance of this psychological approach in people's lives. Enabling courses have an increased number of students utilising them as an alternative pathway to gain access to university. These courses have an important structural role in the development and up-skilling of students to assist with a positive transition into undergraduate studies. The Skills for Tertiary Education Preparatory Studies (STEPS) course offers a unique unit of study which introduces students to positive psychology as a means for students to develop the psychological resilience required on the student learning journey. Positive Learning for University (PLU), takes students on a personal and academic journey where they learn about theories that underpin positive psychology and can apply strategies to themselves personally and to their role as students. This article looks at three concepts that students found most beneficial: positive thinking, signature strengths, and resilience and considers why these resonate with students.
\end{abstract}

Keywords: Mental health; positive psychology; adult learners; optimism; enabling education.

\section{Introduction}

Enabling programs, such as the Skills for Tertiary Education Preparatory Studies (STEP) course offered by CQUniversity Australia, are pathway/transition courses with the key focus on up-skilling and preparing students for the academic rigors they will experience at the undergraduate level of university. The Positive Learning for University (PLU) unit is one of 12 units offered in the STEPS course. Students are introduced to the theories that underpin positive psychology and taught concepts that can be applied to enhance their student journey and meld into the wider context of their life outside the education system. The goal of the unit is to enhance their psychological well-being and teach them concepts that will positively impact on their educational journey. Using the tenets of positive psychology, this unit aims to develop a student's strengths, capacity and virtues rather than focusing on their weaknesses (James \& Seary, 2018). Through the application of learned techniques, students are empowered to change their focus from a negative 'all or nothing' approach to a more positive outlook. The unit considers proactive solutions and strategies which challenge the mould of the 'victim' paradigm and may assist with making the learning journey more meaningful (James \& Seary, 2018). The PLU unit consists of 11 teaching modules and covers 23 core concepts, all of which include examples and exercises for the students to undertake. This unit is not based on developing an academic

This work is licensed under a Creative Commons Attribution 4.0 International Licence. As an open access journal, articles are free to use with proper attribution. ISSN: 2205-0795 
skillset for university, but rather focuses on developing strategies that allow a more optimistic mindset and encourages transferable skills to improve their mental health, well-being and self-efficacy. This article reports on the findings from a research project that investigated which of the 23 concepts the students felt had been most useful for them in both their academic journey and personal lives.

\section{Literature Review}

Today's society has a way of fearmongering and cultivating inflammatory negative reactions. It has become a cultural epidemic and social media is constantly bombarding the viewers with falsehoods and agendas. In addition, mental health issues appear to be increasing with what seems to be a high number of people being diagnosed with mental illness. The National Mental Health survey found that 20 per cent of the Australian population suffers a mental disorder with a significant portion being those aged 16-34 years (Australian Institute of Health and Welfare, 2014). Further to this, the Mental Health Foundation (2014) shared that one in six adults has been diagnosed with a common mental illness at some stage of their lives. An interesting finding comes from the Australian Medical Students' Association [AMSA] (2013) who found that "psychiatric illness is associated with lower educational achievement, decreased employment, lower incomes and lower standard of living" (p.2). Stallman (2010) found that university students displayed significantly higher distress levels (83.9 per cent) compared to the general population (29 per cent). Crawford, et al., (2016) suggest that this is an indication that university students are an 'at risk' population for mental health difficulties and therefore interventions and preventative approaches are required. Depression and anxiety are an endemic part of student life, but it is the student's own perception of what constitutes a fail in their minds that increases the likelihood of depression becoming a diagnosable disorder rather than a passing phase of academic life.

Positive psychology is based on the foundational work of Martin Seligman whose vision was to shift the main focus of psychology from human malfunctioning towards human strengths and optimal functioning (Seligman \& Csikszentmihalyi, 2000). When positive psychology was first introduced as a new branch of psychology, the overarching goal was for psychologists to acknowledge that traditional psychology had in fact neglected its core mission of curing mental illness due to focussing predominately on client's ailments and mental problems instead of helping them to lead more productive and fulfilling lives and identifying and nurturing high talent (Linley et al., 2006). Csikszentmihalyi and Csikszentmihalyi (2006) claim that the perspective of positive psychology "is intended as a corrective both to the value-free stance of experimental approaches ... and to the exclusively pathology-oriented views that have permeated much of clinical psychology" (p. 5). What this means is that unlike traditional psychological therapy, positive psychology exponents ask what is right in a client's world rather than what is wrong in it. The subtle shift in focus allows the client to identify positives rather than dwelling on the negative factors. However, it is important to recognise the important role that the negative situations in life have on a person's ability to grow and develop. Resilience can only be learnt through overcoming obstacles; strategies can only be applied to aspects in life that require help. As Leontive (2006) shares,

All of the negative has some roots in us and in the structure of our lives, as does the positive. We cannot solve the task of preventing negative outcomes if we fail to treat both aspects simultaneously in a unified explanatory framework (p. 50).

This is particularly important in an enabling course where many of the students are the first in their family to attempt tertiary study. They may not have confidence in their ability to achieve at this level of academia due to difficulties experienced during their secondary schooling years, or have low socio-economic status that may have adversely affected their learning journey (James, 2016; Klinger \& Tranter, 2009; Willans \& Seary, 2007). For many of these students, their experience with education has been framed in the negative and therefore, they need to acknowledge the impact that this has on their self-belief in order to allow positive change to occur. Research by Ouwneel, Le Blanc and Schaufeli (2011) postulates that there is a link between positive emotions, an increase in personal resources and an increase in study engagement. This indicates that the PLU unit may have a twofold outcome for the students: increased ability to positively engage with study and an increase in personal resources and coping mechanisms able to be applied into everyday life.

Positive development underpins the PLU unit as the core tenet is around enabling students to apply concepts and strategies that will enhance their well-being, improve resilience and increase their personal resource base. This unit is not based on developing an academic skillset for university but focuses on developing strategies to develop an optimistic mindset with transferable skills to improve a student's mental health, well-being and self-efficacy (James \& Seary, 2018). Positive development is synergetic as it brings benefits not only to the developing person, but to others within their sphere of influence (Leontiev, 2006). Positive development is not a tangible goal that people can reach, but rather something that a person must cultivate all the time with 
incessant efforts. It is something for which a person can take full responsibility for as it is not just about positive emotions or positive traits, but rather the process of their actualisation. Leontiev (2006) postulates that "understanding the ways of managing our own lives must be the most important research and applied task for positive psychology" (p. 52). PLU introduces students to a variety of self-enhancement concepts through the framework of positive psychology and is underpinned by the CHOOSE Happiness Model developed by Dr Timothy Sharp (2007). CHOOSE is a philosophy that Sharp believes enables people to take daily responsibility over their self-development. CHOOSE is a mnemonic for six key strategies which include: Clarity, Health, Optimism, Others and Enjoy (2007). The PLU unit introduces concepts that fit under the CHOOSE philosophy and covers an array of strategies designed to assist students to reflect within themselves and consider ways they can apply these to their own lives. Students are introduced to positive meaning and living with purpose (Wong, 2013); growth mindset (Dweck, 2009); strengths and virtues (Peterson \& Seligman, 2004); health psychology and the link between holistic health and optimism (Sharp, 2009); positive thinking to develop optimism (Seligman, 1992); nurturing positive relationships (Chapman, 2010); and through Fredrickson's (2001) broaden and build theory, students are "able to see how positive emotions can lead to survival through broadening thought-action repertoires and building enduring personal resources" (James \& Seary, 2018, p.3). Research undertaken by Henry (2006) considers a range of counselling techniques and found that their participants "valued approaches based on engaging with the world, being socially embedded, and in some cases building a positive attitude, finding purpose, and orienting toward the future" which link to the very principles taught in PLU under the tenets of Positive Psychology (p.135).

Academic failure is relatively common in higher education. Our own analysis of 2016-17 institutional data from a large, comprehensive Australian university showed that the incidence of academic failure varied across courses with roughly 40 per cent of students failing one or more academic units during their degree. Importantly, academic failure contributed a four-fold increase to the risk of course attrition compared to students who did not fail a unit of study (Ajjawi et al, 2019). Approximately 70 per cent of those who failed persisted with their studies, while 30 per cent dropped out and 58 per cent of those who failed one unit subsequently failed more. Academic failure is often attributed to multiple factors, which suggests that multiple strategies are required for successful course completion following a failure. Furthermore, the diversification of the student body including "the growing realities of non-linear student pathways, diverse student cohorts, and increasingly partial, part-time, deferred and liminal enrolment status" attunes us to the need for flexible and tailored/individualised support strategies (Harvey et al., 2017, p. 7). Given that the majority of students, who fail do persist (Ajjawi et al., 2019), understanding the strategies they use to overcome academic failure might help us to better support students who fail, in all their diversity. In this article, we examine the responses of students who fail and persist, to identify what drives them to continue, the support strategies they seek and how they adapt.

\section{Research Design: Methodology, Process, Data Analysis}

This article reports on the findings from a unit enhancement internal project whereby the educators wanted to ascertain what concepts within the unit students were finding most beneficial to their growth and development. The data were sourced from student assessments that were submitted near the end of each term. As part of a reflective Learning Portfolio Assessment for PLU, students were asked to reflect on which two concepts they felt had the biggest impact on them over the duration of the term and explain their reasonings. There are limitations to the findings as this assessment related predominately from Weeks 5 to Weeks 9, therefore, some students may have been unaware that they could choose concepts from the first 4 weeks of the unit. Data were collected from assessments submitted in Terms 1, 2 and 3 of 2017, and Terms 1 and 2 of 2018 . All responses were collated into an excel document and Thematic Analysis used to categorise and theme the key concepts. The approach suggested by Braun and Clarke (2006) was used to analyse the responses as it identifies, analyses and reports patterns (themes) found within the data. The six phases of Thematic Analysis were followed which ensured that through the analysis, the data were coded, broad themes established, review undertaken to narrow themes with the final step being the writing of the findings (Braun \& Clarke, 2006).

\section{Participants}

The responses from 82 students were used (67 female and 15 male). Ages ranged from 18 to 58 (ages not available for 5 participants). The largest group for this study was the 20-29-year-old age group (42.7\%) and the smallest group was the under 20 year old $(\mathrm{N}=6.1 \%)$ (see Figure 1$)$. 


\section{Figure 1}

Age Range of Participants

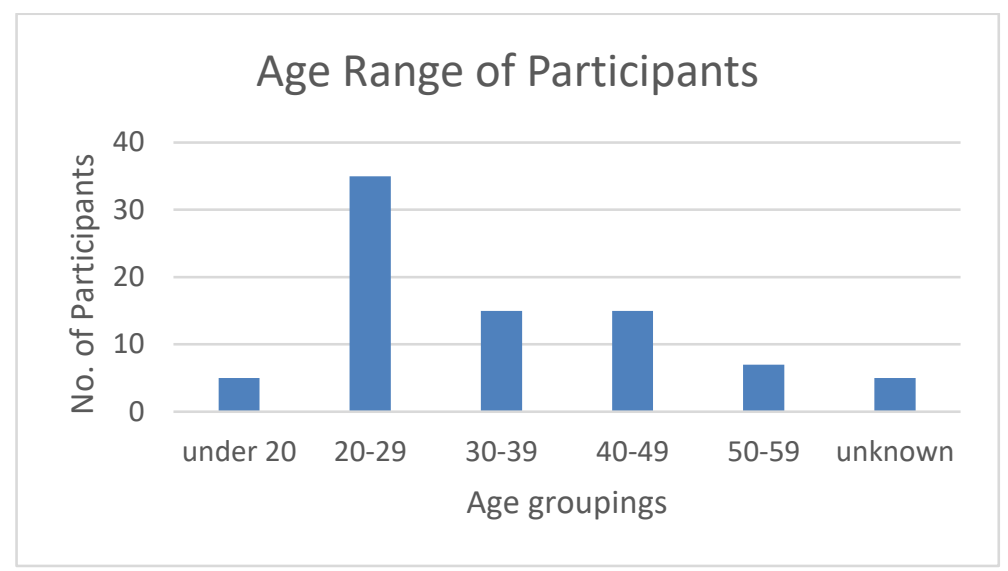

The majority of the participants were female and in the 20-29 age bracket $(\mathrm{N}=25)$ and this was also reflected in the number of males in this group $(\mathrm{N}=10)$. There were no males in the under 20 or 50-59 age groupings (see Figure 2).

\section{Figure 2}

Gender and Age of Participants

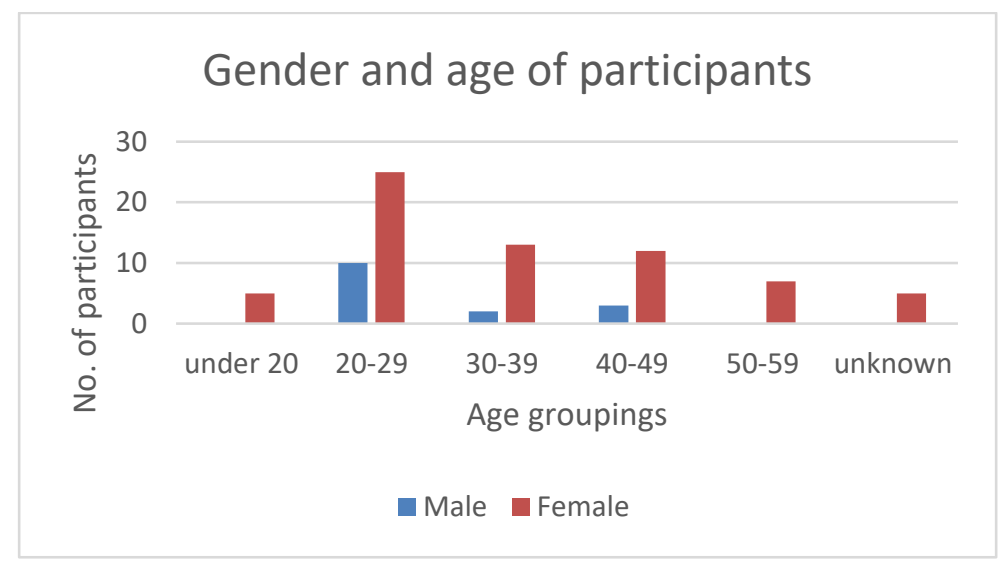

\section{Findings}

Through the analysis, it became evident that there were 3 concepts that really impacted the student cohort over those 5 terms of study. As can be seen in Figure 3, a range of concepts are covered and because each student enters PLU with a wealth of lived experiences, both positive and negative, different concepts can resonate with them quite deeply depending on what is happening within their life at that point in time. However, this article will report on the three concepts that registered as having the most impact on the students. These include 1). Positive Thinking (ANTS vs POTS), 2). Signature Strengths, and 3). Developing Resilience. 


\section{Figure 3}

Student Preferences

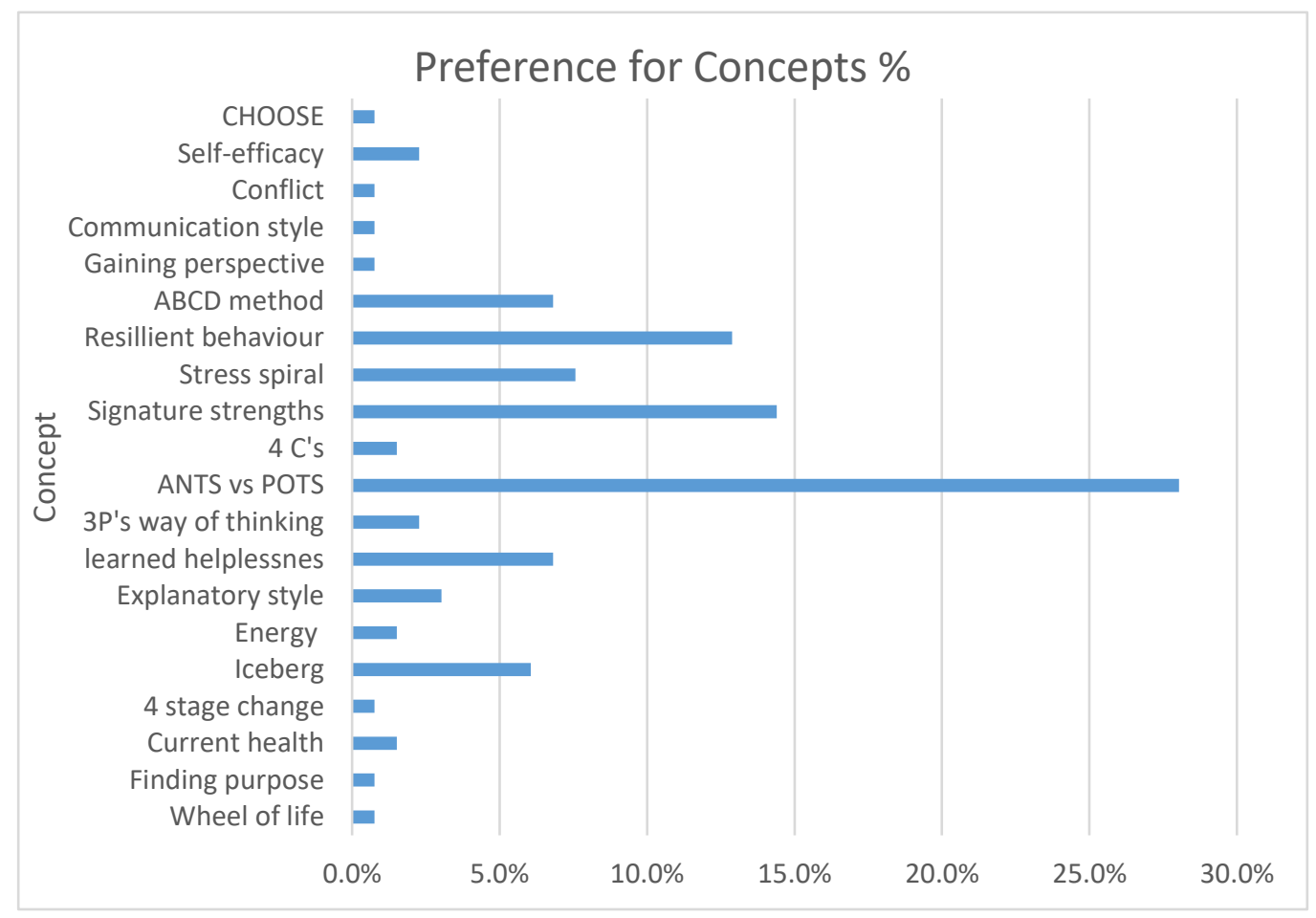

\section{Positive Thinking}

The concept that resonated most with the students was the Automatic Negative Thoughts (ANTS) vs Planting Optimistic Thoughts (POTS) with students expressing that it had empowered them to make positive changes to their thinking processes. Examples of ANTS are Overgeneralisations, Filtering (selective abstraction or focussing on the negatives), All or nothing thinking, Personalising, Catastrophising, Emotional reasoning, Mindreading, Fortune Telling Error, Should statements, Magnification/Minimisation (Sharp, 2018). The ANTS concept explores the way students think about problems and assists them to change their mindset to a more positive, optimistic one, which focusses on moving through the problem, rather than being 'stuck' in a cycle of negative thinking. One student commented that:

... this is especially handy when I am having ANTs regarding my studies. A little arguing with myself and inserting some POTS makes me feel better about myself and gives me a better chance at succeeding in my study and assessments.

Whilst another shared that she utilised the ANTs and POTs throughout her time in undergraduate study by "stopping the negative thought about how I can't do the subject and how dumb I am and shouldn't be here. Instead I'll replace them with more positive/optimistic thoughts to help me get through it". Using the ANTs vs Pots technique appears to assist students in developing their own inherent belief in their ability and capacity to study, which in turn should enhance their likelihood to succeed in study.

Students also cited areas of their life outside the academic environment that they feel have been enhanced by applying what they have learnt around the ANTs vs POTs concept. Frequent comments such as "I have noticed that I am a lot happier and calmer. It's helped me gain confidence which I've never been able to do before. I am able to achieve a better quality of work/life balance." Other students felt that this concept has assisted them with mental health challenges such as depression and anxiety by giving them strategies to change their intrinsic thought patterns. One student shared "I was disposed towards pessimism and still have a tendency to overthink and overanalyse myself into depression and anxiety. These concepts have helped me become more optimistic about myself, others and life." Another shared "I am now a happier person even when adversity strikes. 
Although I still struggle with ANTS, once I develop these skills further, I am confident that they will improve all areas of life by boosting my happiness." It could be intimated that these students now have a newfound 'hope' for a better future as one shared "If it was not for this new truth given to me through this unit, I would be still stuck in that hole of hopelessness."

It was evident that many of the students in this study did not realise that they were viewing their scholastic achievements through a distorted, negative lens until they worked through this module and had the ability to change this viewpoint. Once they had discovered this personal truth, many have worked towards teaching those that they are close to. One student summed up this feeling with:

I had not ever realised that I was able to change my learned behaviours and am going to share this information with my preteen children in the hope they too will remove some ANTS so that leading into their futures they have less POTS to plant because the ANTS are not there to start.

\section{Signature Strengths}

The signature strengths concept required students to complete a 240 question VIA Survey of Character Strengths through the Authentic Happiness website (VIA Institute on Character, 2019) in order to identify their personal strengths. Research conducted by Petersen and Seligman (2004) shares that it is common for people to focus on their faults or weak areas and overlook the aspects of their character in which they are strong. It has been postulated that happy people are more able to identify and use their innate strengths rather than worry about fixing any weaknesses they identify in themselves (Sharp, 2007).

The 24 different character strengths are broken into six subcategories (see Table 1), giving each student a unique profile.

\section{Table 1}

Values and Character Strengths

\begin{tabular}{|l|l|}
\hline Values & Character Strengths \\
\hline Wisdom & Creativity, Curiosity, Judgement, Love-of-learning, and Perspective \\
\hline Courage & Bravery, Honesty, Perseverance, and Zest \\
\hline Humanity & Kindness, Love, and Social intelligence \\
\hline Justice & Fairness, Leadership, and Teamwork \\
\hline $\begin{array}{l}\text { Temperance } \\
\text { Transcendence }\end{array}$ & Forgiveness, Humility, Prudence, and Self-regulation \\
\hline \multicolumn{2}{l}{ (VIA Institute on Character, 2019) } \\
\hline
\end{tabular}

Upon completion of this survey, students identify their personal 'top ten' character strengths and highlight five that they believe are their most prominent signature strengths. They were tasked with relating these strengths to their personal lives and to consider how they could utilise them better in their educational journey. The VIA Character Strengths have a positive focus on personal characteristics, and this is important in negating the ingrained habit of focussing on weaknesses in order to become a stronger person. The underlying goal behind the strengths test is to encourage people to identify their innate strengths and utilise them as it brings enjoyment and meaning to what they are undertaking.

Although a few students linked their signature strengths to their current studies, many made comment about how they saw their individual traits being an enhancement to their post-academia career aspirations with one sharing "knowing my strengths means that I can work to them, and use them to my best advantage, carrying me forward." Another shared from a more personal perspective that "identifying these has given me areas which I wish to nurture and grow in my life", whilst another recognised that "knowing what my greatest strengths are will encourage me to play to my strengths and focus on applying them to work, study and life in general." Students appeared to look at their signature strengths in a more holistic manner through deciding to use their identified strengths to enhance their future, stating that they perceive that it is "going to have a big impact on my future" but also to look at the weaknesses identified and "work on my weaknesses and embrace my strengths". 


\section{Resilient Behaviour}

Unlike the signature strengths which are identifying innate traits, resilience is not seen to be a trait that is inherent in all people, as it is learned behaviours, thoughts and actions that can be developed through experiences. The module that shares around the concept of stress also touches on resilience and uses Poulson's (2008) story of resilience as a base for understanding the concept and suggestions on how to bounce back from negative situations in life. Students were asked to either reflect on a time in their life that they had shown resilience after a major stressor or look to literature for other people that had overcome major life obstacles. Through this, students related the story to Poulson's (2008, p. 39) four steps towards resilient behaviour: Identifying stressors, Recoil, Response, and Rise.

Identification of their own past resilient behaviours caused by both physical and mental challenges resonated with many of the students with them disclosing very difficult times in their personal history and the steps they had taken to recover. Students who are planning on studying 'caring' undergraduate courses put the learnings from this unit into the future context and how they believe that an understanding of the resilience of others will help them in their careers. "Resilience is going to be a key concept I will need to conquer this emotionally challenging career" and the "need to develop a capacity to cope with stress and bounce back, so I am effective in my job of helping people" were a common theme within the comments made about this part of the unit. Fear of failure can be a debilitating disorder, and if it is perceived by a student that they have failed to live up to the standards that they have set themselves, their academic career can be placed in jeopardy. It is by the application of the steps of resilience that they may recover and move forward. In addition to the personal stories, students were inspired by published accounts of the resilience of others and stated that it had changed their life view "knowing what other people go through each day just to get through a normal day has really inspired me to not take life for granted and be grateful for what you do have as life can change within seconds" is a statement that was echoed throughout the comments.

\section{Discussion}

This research impresses on us that there are some students who are wanting change and want to find a way to be more optimistic and look for the positives in life. They are looking for a way to break the mould of the victim paradigm that past experiences and life in general has implied. The social determinants of mental health exert their effects more broadly at the societal level specifically the social determinants of mental health, exemplified by income inequality and poor education are underpinned by unequal distribution of opportunity (Compton \& Shim, 2015). The essence of what the findings have indicated is that these students want hope. They want to believe that life can be better than the hand they were dealt. Hope is the key and this unit gives them hope that they can finally take charge of their mindset and make positive change for themselves and in-turn their families. These findings draw on Freire's (1992) Pedagogy of Hope and many writers and researchers have delved into this theory and drawn conclusions as to how hope can be the impetus for change in people's lives. Webb (2013) describes it as an integral part of human experience whilst Giroux (2002) defines it as a belief that different futures are possible. Dreyer's (2011) perspective believes that inclusive education is a pedagogy of hope; Carl (2011) claims education that strives for peace is a pedagogy of hope; Frick and Albertyn (2011) believe that recognition of prior learning is a pedagogy of hope; Carolissen et al. (2011) claim that the enactment of emotion in teaching and learning is a pedagogy of hope. In all the research, there is a thread of similarity that pins success on the notion of 'hope' and this is critical in the realms of positive psychology. The majority of articles refer in some sense to people who are disadvantaged or have had barriers to learning. Weingarten (2010) argues that hope should focus on what is achievable and should encompass the dreams, visions, wishes, values and meanings of ordinary people. The hope that underpins the findings from this unit would be what Pettit (2004) calls resolute hope whereby it is "a process by which we actively adopt a particular attitude and construct a supportive and stable image around which to organise our feelings and actions" (p. 163).

Further to the notion of hope is that of care and nurturing. Crawford, et al., (2016) suggest that two core principles that are important in supporting student well-being is a "culture of care" and a "culture of self-development and growth" (p. 14). What we see reflected in the ethos of PLU include both these aspects. This unit is presented in such a way that the students are in the midst of self-development but within a supportive environment. The unit uses a culture of care in its support model whereby the educator is in constant contact to engage students and build rapport, so the students feel they have someone to talk to when required. Furthermore, the whole purpose of the unit is to give students the tools to assist in developing and improving their own personal well-being. 


\section{Conclusion}

"To hope is to perceive oneself as capable of producing plausible routes to one's desired goals and to perceive oneself as capable of achieving one's goals by moving along the identified pathways" (Webb, 2013). Hope can be cultivated; it is a thinking pattern that needs to be instilled as it is a positive process of self-regulation. Through this unit of study, PLU introduces students to a range of concepts that are underpinned by positive psychology. This research highlighted the three key concepts that students found benefited them the most. What is evident is that the students valued the changes they saw in their personal mindsets through strategies that refuted negative thought patterns and replaced them with a more optimistic outlook. In addition, they gained an appreciation as to how their personal strengths nurture habits of hope as they begin to understand how the utilisation of these strengths add meaning to their daily activities that will produce plausible routes to their desired goals of well-being. Further to this, understanding how to develop resilience demonstrates that behavioural aspects associated with resolute hope can be personally transformative.

\section{References}

Australian Medical Students' Association [AMSA]. (2013). AMSA Student Mental Health and Wellbeing Policy. http://www.amsa.org.au/advocacy/official-policy

Australian Institute of Health and Welfare. (2014). Mental health services-in brief 2014. Cat. no. HSE 154. C. http://www.aihw.gov.au/WorkArea/DownloadAsset.aspx?id=60129549620

Braun, V., \& Clarke, V. (2006). Using thematic analysis in psychology. Qualitative Research in Psychology, 3(2), 77-101. https://doi.org/10.1191/1478088706qp063oa

Carolissen, R., Bozalek, V., Nicholls, L., Leibowitz, B., Rohleder P., \& Swartz. L. (2011). Bell hooks and the enactment of emotion in teaching and learning across boundaries: A pedagogy of hope. South African Journal of Higher Education. 25(1). 157-167.

Chapman, G. (2010). The 5 love languages: The secret to love that lasts. Northfield.

Compton, M. T. \& Shim, R. S. (2015). The social determinants of mental health. The Journal of Lifelong Learning in Psychiatry, 13(4), 419-425. https://doi.org/10.1176/appi.focus.20150017

Crawford, N., Lisciandro, J., Jones, A., Jaceglav, M., McCall, D., Bunn, R., Cameron, H., Westacott, M., \& Andersen, S. (2016, December 1-2). Models of support for student wellbeing in enabling programs: Comparisons, contrasts and commonalities at four Australian universities. [Paper presentation] Foundations and Bridging Educators New Zealand. Wellington, New Zealand. http://fabenz.org.nz/wp-content/uploads/2016/12/Nicole-Crawford.pdf

Csikszentmihalyi, M., \& Csikszentmihalyi, I. S. (Eds.). (2006). A life worth living: Contributions to positive psychology. Oxford University Press.

Dreyer, L. (2011). Hope anchored in practice. South African Journal of Higher Education, 25(1), 56-59. https://www.ajol.info/index.php/sajhe/article/view/72529

Dweck, C. S. (2009). Mindsets: Developing talent through a growth mindset. Olympic Coach, 21(1), 4-7.

Fredrickson, B.L. (2001). The role of positive emotions in positive psychology: The broaden-and-build theory of positive emotions. American Psychologist, 56, 218-226. https://psycnet.apa.org/doi/10.1037/0003-066X.56.3.218

Freire, P. (1992). Pedagogy of hope: Reliving pedagogy of the oppressed. Continuum.

Frick, L. \& Albertyn, R. (2011). Recognition of prior learning in promoting lifelong learning: A pedagogy of hope or a shattering of dreams? South African Journal of Higher Education. 25(1). 145-156. https://www.ajol.info/index.php/sajhe/article/view/72535

Giroux, H. (2002). Neoliberalism, corporate culture, and the promise of higher education: The university as a democratic public sphere. Harvard Educational Review. 72(4). 425-464. https://doi.org/10.17763/haer.72.4.0515nr62324n71p1

Henry, J. (2006). Strategies for achieving well-being. In M. Csikszentmihalyi and I. S. Csikszentmihalyi. (Eds). A life worth living: Contributions to Positive Psychology. Oxford University Press.

James, T. (2016). The juxtaposition of STEPS to the undergraduate arena: The lived experience of transitioning into undergraduate study. Australian Journal of Adult Learning, 56(2), 250-267. https://www.ajal.net.au/the-juxtaposition-ofsteps-to-the-undergraduate-arena-the-lived-experience-of-transitioning-into-undergraduate-study/

James, T., \& Seary, K. (2018, November 29-30). What's so positive about positive psychology in an enabling program. [Paper presentation] Foundations and Bridging Educators New Zealand. Wellington, New Zealand. http://fabenz.org.nz/proceedings-of-the-fabenz-conference-2018/ 
Klinger, C. \& Tranter, D. (2009, November 25-27). Firm foundations for the future. In T. Bedford, H. Huijser \& S. Muller (Eds). [Paper presentation] Enabling Pathways Conference. Toowoomba, Australia.

Leontiev, D. (2006). Positive personality development: Approaching personal autonomy. In M. Csikszentmihalyi and I. S. Csikszentmihalyi. (Eds.). A life worth living: Contributions to Positive Psychology. Oxford University Press.

Linley, P. A., Joseph, S., Harrington, S. \& Wood, A.M. (2006). Positive psychology: Past, present, and (possible) future. The Journal of Positive Psychology, 1(1), 3-16. https://doi.org/10.1080/17439760500372796

Mental Health Foundation (2014). Mental Health Foundation: Quick Facts and Stats. https://www.mentalhealth.org.nz/assets/Uploads/MHF-Quick-facts-and-stats-FINAL.pdf

Ouwneel, E., Le Blanc, P. M., \& Schaufeli, W. B. (2011). Flourishing students: A longitudinal study on positive emotions, personal resources, and study engagement. The Journal of Positive Psychology, 6(2), 142-153. https://doi.org/10.1080/17439760.2011.558847

Pettit, P. (2004). Hope and its place in mind. Annals of the American Academy of Political and Social Science. 592(1). 152165. https://doi.org/10.1177\%2F0002716203261798

Poulson, I. (2008). Rise. Macmillian.

Peterson, C. \& Seligman, M.E.P. (2004). Character strengths and virtues: A handbook and classification. Oxford University Press.

Seligman, M.E.P. (1992), Learned optimism. Pocket Books.

Seligman, M. E., \& Csikszentmihalyi, M. (2000, January). Positive Psychology: An Introduction. American Psychologist, 55(1), 5-14. http://www.bdp-gus.de/gus/Positive-Psychologie-Aufruf-2000.pdf

Sharp, T. (2007). The happiness handbook. ( $2^{\text {nd }}$ ed.). Sydney, Australia: Finch.

Sharp, T. J. (2018). Examples of Unhelpful Thinking. https://www.drhappy.com.au/wp-content/uploads/Examples-OfUnhelpful-Thinking.pdf

Stallman, H. M. (2010). Psychological distress in university students: A comparison with general population data. Australian Psychologist. 45(4), 249-257. https://doi.org/10.1080/00050067.2010.482109

VIA Institute on Character. (2019). VIA Institute on Character. http://www.viacharacter.org/www/Character-Strengths\#

Webb, D. (2013). Pedagogies of hope. Studies in Philosophy and Education. 32(4). 397-414. https://doi.org/10.1007/s11217012-9336-1

Weingarten, K. (2010). Reasonable hope: Construct, clinical applications and supports. Family Process. 49(1), 5-25. https://doi.org/10.1111/j.1545-5300.2010.01305.x

Willans, J., \& Seary, K. (2007). I'm not stupid after all: Changing perceptions of self as a tool for transformation. Australian Journal of Adult Learning, 5(3), 434-452.

Wong, P. (2013). Viktor Frankl's meaning seeking model and positive psychology. http://www.drpaulwong.com/viktorfrankls-meaning-seeking-model-and-positive-psychology/

\section{Please cite this article as:}

Walters, V., \& James, T. (2020). ANTS and POTS: Do they change lives? Students perceptions on the value of positive psychology concepts. Student Success, 11(1), 46-54. https://doi.org/10.5204/ssj.v11i1.1461

This article has been peer reviewed and accepted for publication in Student Success. Please see the Editorial Policies under the 'About' section of the Journal website for further information.

Student Success: A journal exploring the experiences of students in tertiary education

(c) (1) This work is licensed under a Creative Commons Attribution 4.0 International Licence. As an open access journal, articles are free to use with proper attribution. ISSN: 2205-0795 